\title{
The design consultancy as a hub for global projects - a networked design process across emerging countries
}

\author{
Carlo Franzato ${ }^{a}$, Nora Morales Zaragoza ${ }^{b}$, Monica Orozco Torres ${ }^{c}$ \\ Universidade do Vale do Rio dos Sinos \\ bUniversidad Autónoma Metropolitana \\ Empatitis \\ e-mails: cfranzato@unisinos.br; nmorales@correo.cua.uam.mx; monicaorozco@empatitis.com
}

\begin{abstract}
This paper presents a research and design experienced by a Latin American consultancy across Mexico, Brazil and India. This work aimed to, committed by an US electronics company, define a set of principles to design a new educational device for emerging countries. We framed the human-centred and collaborative design approach used during the experience, within a broader disciplinary tendency that gives a central position to socio-cultural aspects. Then we argue that design consultancies can evolve their role paying attention to these aspects, becoming crucial hubs to develop global projects in a connected world. Through these hubs, foreign corporations could understand and enter in local markets.
\end{abstract}

Keywords: design network, collaborative design, design consultancies, emerging countries, electronics products.

\section{Introduction}

According to Bonsiepe (1985), the central factor for the development issue in emerging countries is the capability of evolving its own technology autonomously. In the design discourse, it means the capability of evolving design as a process (CELASCHI et al., 2008), in order to constitute a technology for the innovation of the organizations.

Countries as Mexico, Brazil or India, are characterized by multiculturalism or real miscegenation. Practicing design in these countries with the consciousness of their cultural idiosyncrasies could indicate new design possibilities (DE MORAES, 2006).

Local diversity is an essential asset here, considered as a cultural background for elaborating original design processes as well as a working matter during the development of the same processes. In this direction, in the last decades designers have developed many strategies, methods and tools for designing with a renewed sensitivity that gives a central position to the user. We focus our attention on two strongly research-based approaches: human-centred design - that intends the user as the purpose of the design process (INTERNATIONAL..., 2010), and co-design that intends the user as a protagonist of the design process (SCRIVENER, 2005).

At the same time, global connection enables to scale the relevance of the design activity. It allows designers and organizations to collaborate or compete independently from where they are from. Beside this, their results could be addressed to people in many parts of the world, even when conceived to meet specific local needs (QUESENBERY; SZUC, 2012).

In this direction, the paper aims at discussing how the role of design consultancies is changing, facing the challenge of a connected world.

We study the case of a research and design process developed by Insitum, a networked design consultancy Mexico City-based. A US electronics company commits to Insitum to explore aesthetics patterns and technology expectations across Mexico, Brazil and India. The company was searching for a set of principles to design a new educational device for emerging countries.

The consultancy applied a special practice, frequently used to create global products, that starts with simple translations in order to identify cultural differences, towards a deeper understanding of people in different places (QUESENBERY; SZUC, 2012). This practice was very helpful to unlock cultural perceptions and norms of the local markets and to understand how these ones are affected by changes from other forces of globalization.

As a result, considering the reasons why a US software company has not committed this project to a US design consultancy of its portfolio, but to a Mexican one, we point out that consultancies based in the main cities of 
Latin America could serve as strategic hubs for foreign corporations connecting with national realities, developing international projects and entering in local markets. Thus, the design consultancies function of transferring technology or prospecting new markets (BERTOLA; TEIXEIRA, 2003) is situated within the globalization dynamics.

\section{Design and research in a connected world}

The shift to a knowledge economy is taking place in organizations as part of this networked world where talent is the key access to success (HAGEL; SEELY; DAVISON, 2010). In order to attract and maintain the talent, a company needs to evolve itself as a creative environment and develop collaboration with external partners to assure a continue fertilization of such environment. In this sense, the design consultancy could become a good ally.

In the age of information and global connectivity that we experiment nowadays, the geographic, cultural, and language barriers, combined with an overload of conflicting messages available through different media and the variety of consumer choices, have created an overwhelming need for clarity and pertinent solutions to create positive outcomes for life and business across global cultures (VISOCKY O'GRADY; VISOCKY O'GRADY, 2008).

Advances in technology and communication are driving substantial changes and the emergent markets like Middle East, Latin America and Africa are rapidly incorporating knowledge technology to their increasing economic growth. In this direction, globalization 3.0 allows individuals to contribute and compete, no matter where they are from. Opportunities are being created, especially in markets that were in an economic disadvantage (QUESENBERY; SZUC, 2012).

In this scenario, the focus on the latent needs of people and their relations to a particular context and culture - in order to enhance the way they live, work, learn and play through products and services - have become a key objective of design, working with the government, corporations and educational institutions.

Practice is moving toward collaborative approaches that enable the creation of innovative products, messages, environments, services and overall experiences for a global context. For a company looking for opportunities in a global market there is a way to understand the cultural differences of each culture and finally achieve a deeper understanding of people in different places (VISCIOLA, 2012 apud QUESENBERY; SZUC, 2012).

It takes a long time, perhaps a whole lifetime, to really understand a culture, so organizations need local antennas to understand global projects and develop ideas for new products that will meet local needs and could be good for people in other parts of the world (QUESENBERY; SZUC, 2012).
Human-centred design places the end user at the centre of the design concern and it is driven by research. Participation of users during the design process provides valuable insight into needs, behaviour and expectations of a target audience. This approach has been evolving to a more involved role of the user into one of co-creator and this intersection generates new patterns and spaces of design (SANDERS, 2005).

At Illinois Institute of Technology (IIT) researchers and designers have been developed a methodology and a toolbox for human-centred design. In this institute, the average entering age of students is 28 , and half of them come from professional designer background while the rest comes from a variety of fields like as engineering, social sciences, architecture, and business (VANPATTER; WHITNEY, 2004). Half of the students come from other countries outside the United States, pursuing a specialization in an education that will help them to be leaders in the planning and developing of communications, products and design (VANPATTER; WHITNEY, 2004).

The IIT methodology is not fixed, but focuses on a set of methods and tools that can be adopted and adapted, from time to time, to act in a specific framework. The idea of IIT methodology is defined by a general process model divided in four phases (VANPATTER; WHITNEY, 2004).

1. Understanding context: focusing on and identifying user activities, core technologies, and business forces.

2. Identifying patterns: reframing the problem and creating criteria for success.

3. Creating innovations: proposing system of products messages, environments and services that create experiential value for the user and economic value to the client.

4. Communicating ideas: producing prototypes and scenarios that help organizations understand the value of the new ideas.

This approach gives enough flexibility to adapt to different contexts and cultures and that might be their main advantage when international students go back to their country with the knowledge of the processes of creating innovations.

\section{Research method and unit of analysis}

This research started from an interest in studying collaborative design networks within Latin-American region, with a specific focus on the collaborations weaved by design consultancies.

Our same research team is an international network of design researchers and designers from Mexico and Brazil. 
We began making an inventory of design consultancies that work across different Latin-American countries. Then, we collected cases of design processes developed by the agencies.

We chose to study a design process developed by Insitum, a networked design consultancy established in Mexico City in 2002. It has branches in São Paulo, Bogotá, Buenos Aires and Chicago. Insitum develops strategic solutions for companies with interests in Latin American and Hispanic markets, through design processes that give a predominant importance to design research. Its trademarked motto is "innovation through research".

The client was a US leading semiconductor manufacturer. The briefing was to develop a set of principles to design a new educational device for emerging countries. The company was interested in better understanding the design language and technology expectation of the target markets, i.e. Mexico, Brazil and India.

Since Insitum has no branches in India, the company selected an Indian design consultancy for the fieldwork there, paying attention that this third part would adopted the same approach of Insitum.

The chosen case helps us to explore important issues of our area of interest. In fact, we chose a global design collaboration between three organizations across four countries, including the US beyond Mexico, Brazil and India (see Figure 1). The involved designers considered cultural idiosyncrasies of these countries, discussing the possibility of a cross-cultural design dialogue. Finally, they adopted a human-centred design approach with the practice of many co-design sessions.

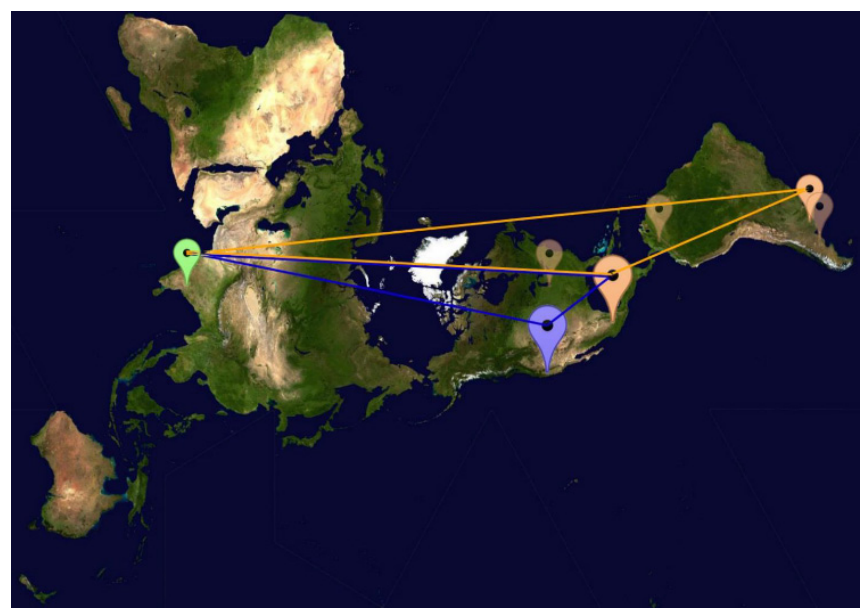

Figure 1. The design network across Mexico, Brazil and India: the electronic company headquarter is marked with a blue pin; the involved Insitum's offices are marked with a solid orange pin, while the others are marked with a translucent orange pin; finally, the Indian partner is marked with a green pin (elaboration by the authors on the Buckminster Fuller's Dymaxion map).
In regards to data we used, we collected contracts, design protocols, intermediary outputs, results of the design activity and final reports. Beside this, we realized interviews with one of the founder and at the moment chair of Insitum, and with a designer involved in the process. During the data collection process, the designer joined the research teamwork, since she demonstrated an authentic interest for the theoretical discussion of the case. The design consultancy has been working hardly on its organizational strategies to improve the networking between all the branches, and the study of the case appeared an opportunity to reflect upon it from other point of view.

It could be a limit of our study, since the influence of the designer could be partial, even if not intentionally. We valued this aspect and finally we decided that her participation would enrich our discussion with observation from a very different perspective. Especially when working on complex networks, this is a meaningful benefit. As suggested by Edgar Morin (2005), the limits between the researcher, its objects and the environment become even more weak and transient.

\section{The research and design process}

The first time the company got in touch with the consultancy, was to receive assistance in understanding educational systems in Mexican and Brazilian emerging markets. Even though the company could count on proper research capabilities, it lacks of local support in the target markets. As stated by a member of the teamwork that works on this project, «the company wanted Insitum to be their eyes, guide and interlocutor throughout the research process in order to understand cultural habits, barriers and opportunities for technology devices in educational current programs».

In this first research, the two organizations deepened how national educational systems worked, both private and public. They mapped them to understand where new opportunities could be in order to set the company's strategy.

Afterwards, the company got in touch with Insitum again to collaborate in the subsequent project we studied. As we anticipated, the briefing was to develop a set of principles to design a new educational device for emerging countries, focusing on their design language and technology expectation. The research and design process might consider the differences between the perceptions of parents and sons, genders and groups of age within a single country, as well as across the three countries, highlighting the different sensitivities.

Meanwhile, the client was studying economic issues by itself.

In the next paragraphs, we analyse the four phases of the developed design process. As set by the teamwork, they are planning, fieldwork, analysis, and deliverables elaboration. 
Planning. In order to fulfil the client's need, Insitum Mexican head office, Brazilian branch and the Indian consultancy - working horizontally - designed a proposal to define method, tools and the chronogram. After a couple of interactions, the company accepted the proposal integrally.

Considering the protocol, all the offices assembled a team of three consultants, generally mixing two designers with a sociologist. They have worked on the project during a period of 10 weeks.

Figure 2 is a visualization of the process protocol developed by the consultancies. Each phase of the process is related to the main tasks and the software they would use to communicate between them or with the company.

Besides the email that was the principal tools for daily communication, they used a web-based project management platform for remote collaboration, VoIP technology for alignment meetings and working sessions, and an online data storage service. This way, they shared the knowledge they were building along the established time frames.

Still during the planning phase, the three teams carried out a preliminary desk exploration, collecting data on the target users and their lifestyle, specifically on fashion trends, technological habits and educational environment.

The designers did not structure this activity, since its main purpose was to acquaint themselves with the design theme and structure the following phase. This way, they outlined the interview protocols and the co-design sessions.

Any team developed a first proposal for both the interviews and the co-design sessions, sharing it with the others and the client. Received their feedback, they started to work on a final common proposal.
They did not work straight on a common proposal, in order to respect the cultural differences of the contexts in which each team had to work. Concerning the interviews, some questions could be meaningful in one country, but not in the others. Moreover, some questions could even generate inconvenient misunderstanding. Concerning the co-design sessions, the trickier moment was the initial approach to the non-designers, i.e. children, teenagers and their parents.

During the planning phase, another problematic issue was the translation of the concepts under investigation between English, Spanish, Portuguese and Hindi. In fact, some concepts were essentially untranslatable and neither the use of images could help effectively.

Fieldwork. The main activities of the fieldwork were the in-depth interviews and the following co-design sessions. The first one provides new elements for the development of the second.

In all, these activities involved 81 participants between children, teenagers and parents (25 in India, 32 in Mexico and 24 in Brazil). They interviewed three different target profiles: students between 6 and 11 years old, and between 12 and 16 years old, besides parents. In all, the three teams realized 21 interviews. Table 1 summarizes the number of the interviewees per profile and country.

The teams realized the in-depth interviews at the home of the interviewees, to explore also their context. A team member had the rule of interviewer, while the other two were camera operator and photographer. This way, the team could collect different types of data for the further analysis. Figure 3 present an example of the photos taken by the photographer of the Mexican team.

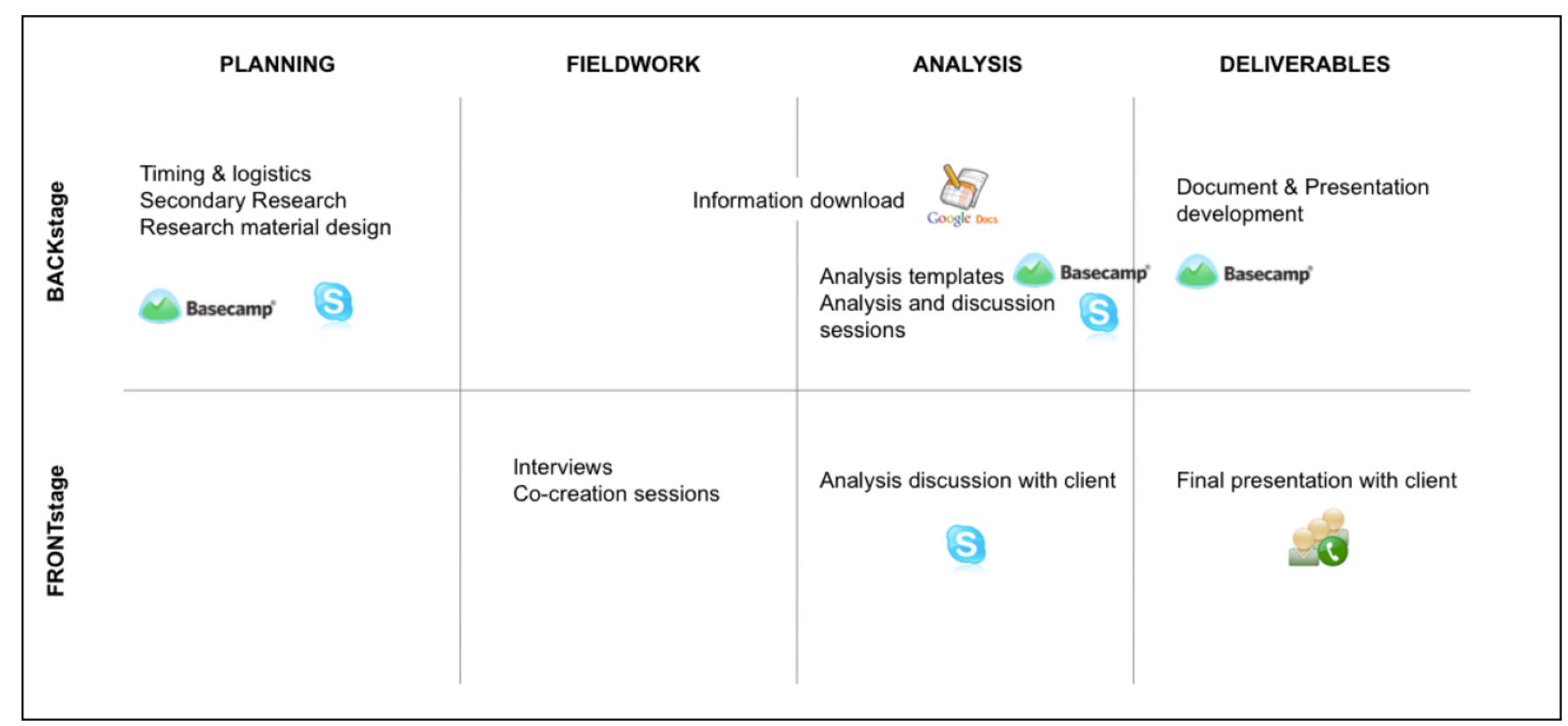

Figure 2. Visualization of the process protocol elaborated by the teams during the planning phase. 
Table 1. Profile and number of interviewees.

\begin{tabular}{|l|c|c|c|}
\hline \multicolumn{1}{|c|}{ Profile } & India & Mexico & Brazil \\
\hline Students 6-11 & 4 & 2 & 2 \\
\hline Students 12-16 & 3 & 2 & 2 \\
\hline Parents & 2 & 2 & 2 \\
\hline Total per country & 9 & 6 & 6 \\
\hline
\end{tabular}

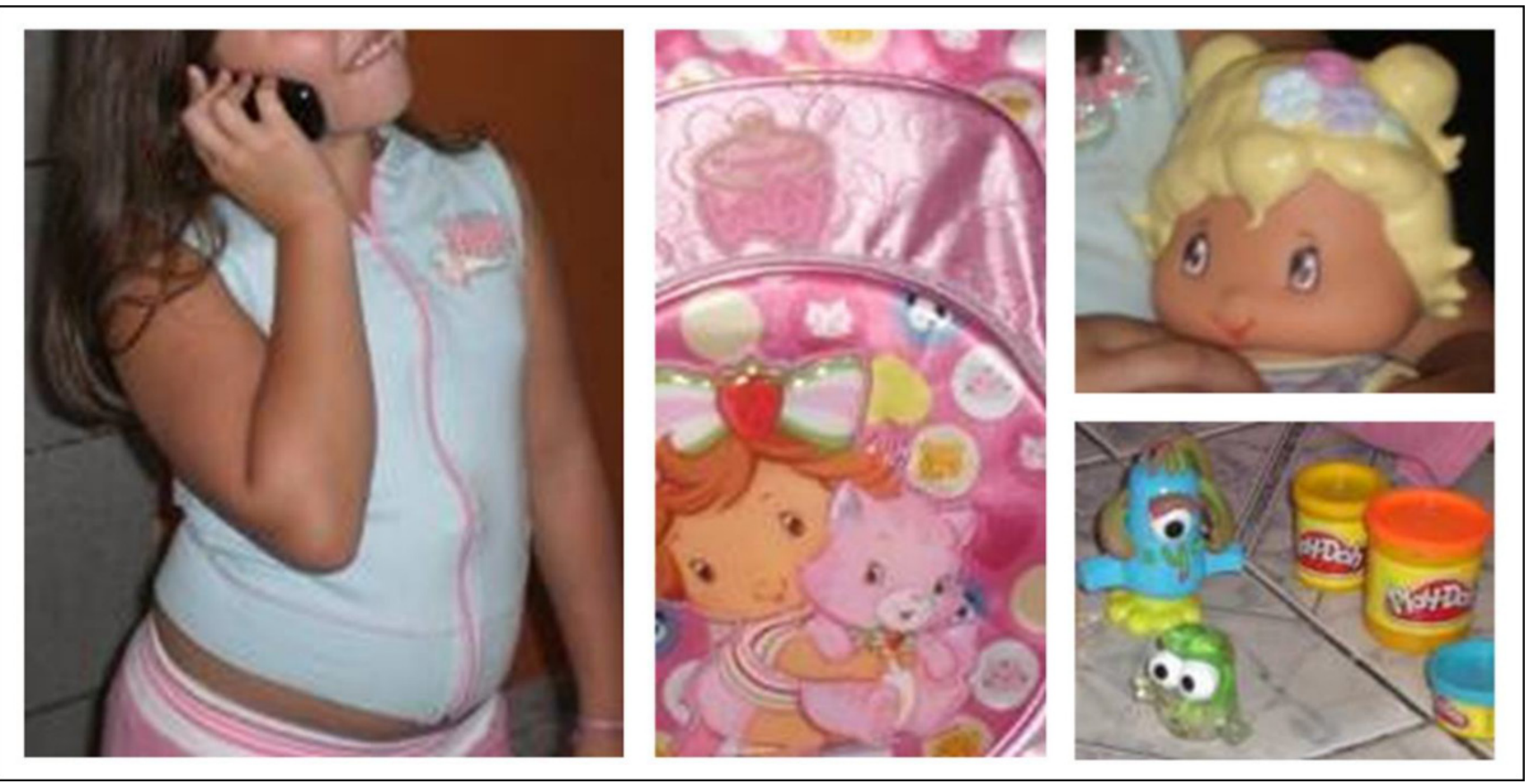

Figure 3. Photos taken by the photographer of the Mexican team.

After the interviews, the teams organized the co-design sessions.

Insitum designers use to organize group sessions with users, in order to discuss a specific topic. In the practice of the consultancy, a co-design session is a special type of group sessions that involves users within a process to design concepts for new products or services, through different pre-planned exercises that facilitate their expression. In a co-design session, the goal remains the same, but the discussion springs from the design process and flows along it.

Through the co-design sessions, designers wanted to deepen the interview results, exploring the design principles that the desk research and the interviews started to outline.

The co-design session involved four different target profiles: students between 8 and 10 years old, between 11 and 13 years old, and between 14 and 17 years old, besides parents. We can notice that the age ranges varied from the previous ones. The interviews suggested moving the interest to older children and teenagers. Moreover, the ranges were diminished in order to homogenize the skills of the participants and facilitate the collaboration between them.

Indian and Brazilian teams organized 4 co-design sessions, involving 18 participants. The Mexican team organized 5 co-design sessions (since they repeated the one with the students between 8 and 10 years old), involving 62 participants. The interviewees were not involved during these sessions. Table 2 summarizes the number of participants per profile and country.

During the sessions, the participants realized three types of exercises. The first one was the exploration of the emerging design values that the teams were discussing between them and with the client, in light of the initial briefing, the results of desk research and the interviews. "Rugged", "kid friendly" or "fun" are examples of these values. Designers showed figures and real objects, previously collected during the desk research, to understand how they fit to those design values. This way, they built specific polarity maps.

The second exercise explores colour and material perception. For example, the participants had to place colours in the areas of a conceptual map, linking them 
to concept like "different/unique", "strong/tough", "cool/trendy" or "just for my child" (Figure 4).

In the third exercise, participants designed their own device, speculating its main functions and form, detailing its special features (Figure 4). This way, participants concretized the different concepts they were thinking over.

Analysis. All the data collected during the interviews and the co-design sessions were organized and shared between the teams using the web-based project management platform and the online data storage service.
Then, the teams established the key questions for the local analysis sessions. Thus, each team worked on its own, assembling their outcomes' information. They dialogued more intensively during this phase, by VoIP calls or commenting the documents. Anyway, they maintained rather independence in order to foster local insights.

They organized the data through tables such as the one in Figure 5. It associates different types of an object, in this case bags, to the design values.

Table 2. Profile and number of participants per co-design sessions.

\begin{tabular}{|l|c|c|c|}
\hline \multicolumn{1}{|c|}{ Profile } & India & Mexico & Brazil \\
\hline Students 8-10 & $4 \times 1$ & $6 \times 2$ & $4 \times 1$ \\
\hline Students 11-13 & $4 \times 1$ & $6 \times 1$ & $4 \times 1$ \\
\hline Students 14-17 & $4 \times 1$ & $4 \times 1$ & $4 \times 1$ \\
\hline Parents & $6 \times 1$ & $4 \times 1$ & $6 \times 1$ \\
\hline Total per country & 18 & 26 & 18 \\
\hline
\end{tabular}

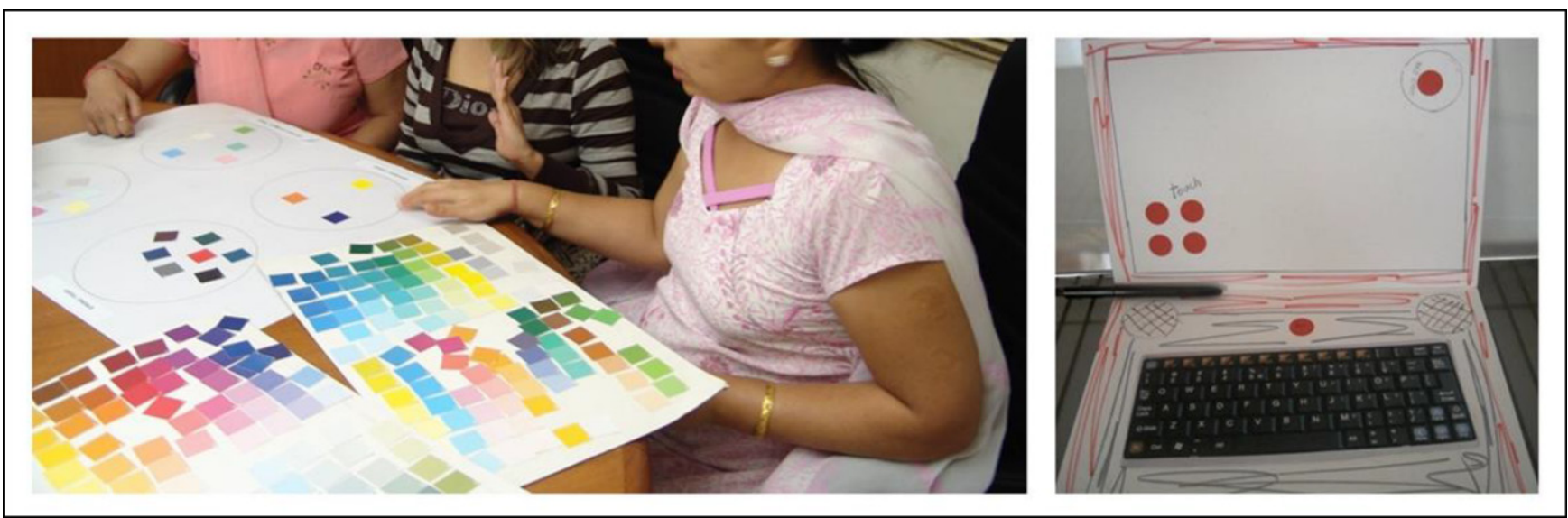

Figure 4. The photos are related to the co-design sessions. The photo on the left is of the Indian session with parents, while the one on the right shows the result of a Mexican session with students.

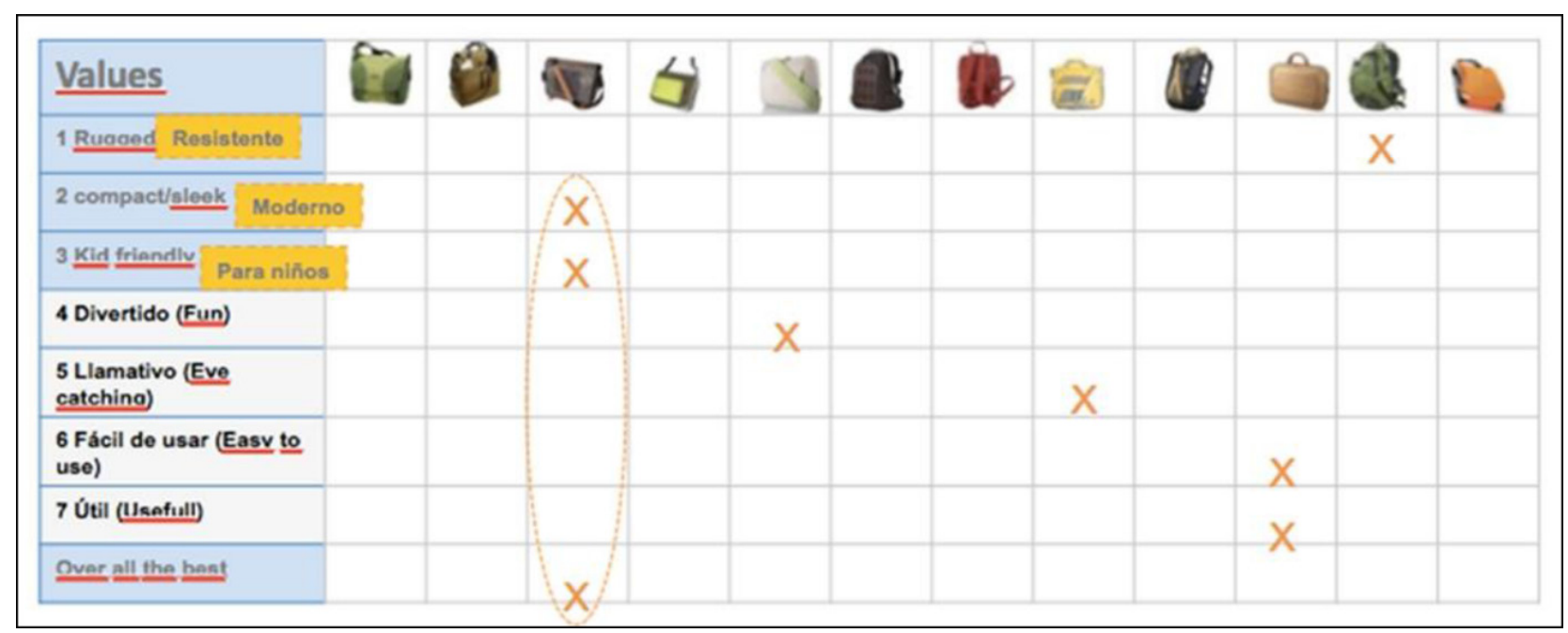

Figure 5. Table elaborated by the Mexican team to aid the discussion of the design values. 


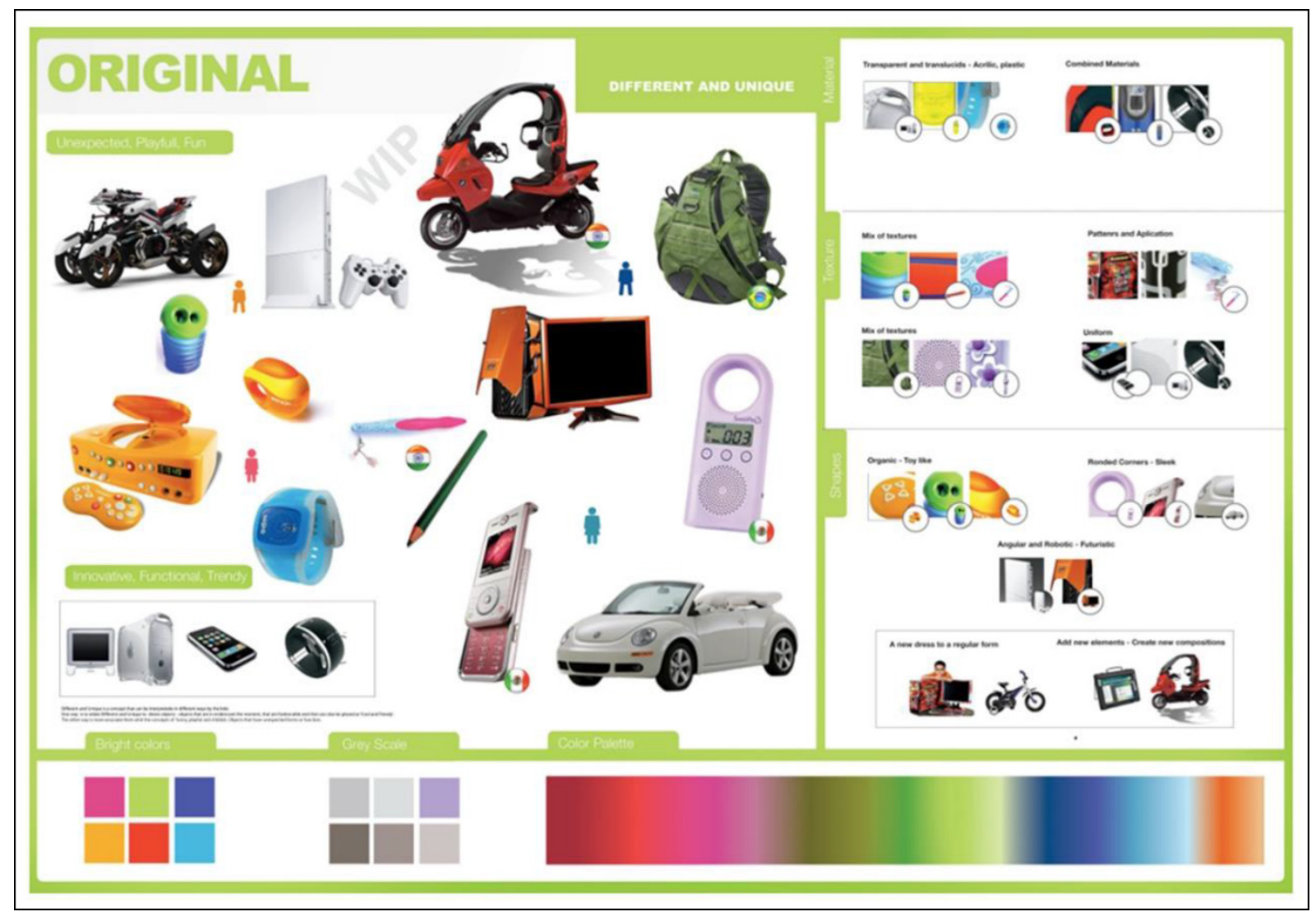

Figure 6. A moodboard elaborated by the teams for the "original" broad concept.

Afterwards, the teams began a collective discussion, synthesizing its results through moodboards. These elaborations collect many different items that appear possible to link to each other, in a unique visual panel. Under the "original" broad concept, for example, Figure 6 collects different types of objects that stand out because unexpected, playful and fun, or because innovative, functional and trendy, a selection of colours and a chromatic palette, and a series of details that explore formal, material or textural issues.

Despite the difficulties of a remote collaboration, the phase tasks development was reasonably easy. The teams have produced similar outcomes during the previous fieldwork phase, so that the data collected by the different teams resulted consistent and their elaboration viable. Moreover, the teams knew exactly what to do and for what, so that the activities moved toward the goals of the phase clearly.

Deliverables elaboration. By this phase, the Brazilian team ended its participation in the project, while Mexican and Indian teams carry on with the conception of a new educational device for emerging countries. The concept had to summarize the whole results of the analysis phase, not the ones obtained in a single country. In fact, the teams found that the most significant differences were not about

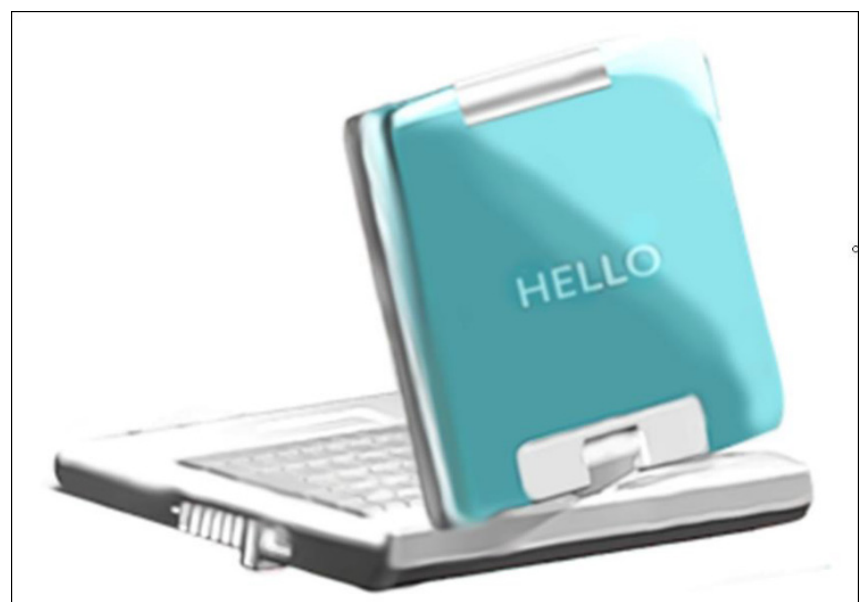

Figure 7. A concept designed by the Mexican team for teenage girls.

the cultures of the three countries, but the age range and the gender of the students. Thus, Mexican team conceived concepts for teenage girls (Figure 7) and boys, while the Indian team conceived concepts for little girls and boys.

Afterwards, each team collected its results using a template developed by Mexican team. The same was responsible to organize the report for the client (Figure 8). 


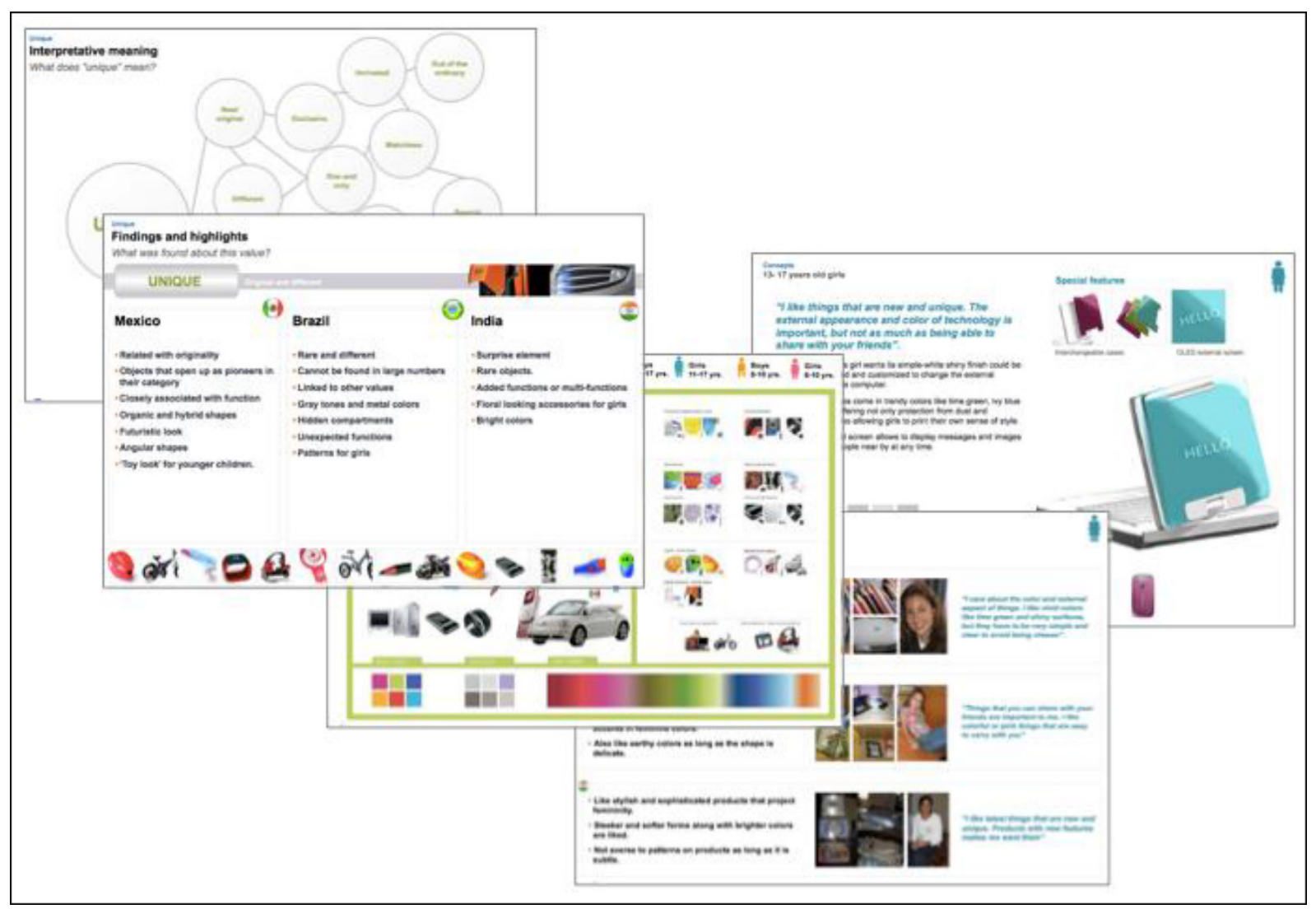

Figure 8. Part of the template developed by the Mexican team to organize the final report.

Finally, it was organized a videoconference with all the teams and the client, to present the whole process, the final results and deliver the document.

The client did not use these concepts. Otherwise, the concepts served to visualize the design principles for new educational devices for emerging countries.

\section{Conclusions}

After the description and analysis of the case, it is possible to underline four results of our work. The former two are on the human-centred and collaborative design approach used in the design experience, stressing the importance of research and its relation with the development of new products. The latter two are on the form of organization used in the process, i.e. the design network that linked the client within the emerging countries, proposing the design consultancy as a strategic hub for the development of global projects.

Importance of research. Confirming the Insitum motto "innovation through research", research practice is crucial in the experience that the design consultancy developed. We observed that the most part of the process focused on research tasks. The second phase (fieldwork), certainly the more demanding and relevant one, was developed through two main activities, i.e. in-depth interviews and the co-design sessions. If the former one is evidently a research activity, also the latter one could be considered similarly. The co-design sessions served the purpose to collect information on the users' needs, behaviour and expectations, not actually to design a new technological device.

Relation between research and development. The design of the devices occurs only in the final stage, with a minor effort by the design teams. The Brazilian one did not even take part to this stage. Afterwards, the design of new products was not the unique goal, nor even the most important one. The general goal of the experience was to foster a contribution for the strategy development of the company within the new markets.

This way, the final renders (as the one showed in Figure 7) seem to be a way to represent and summarize the research, more than real concepts for new products. As a consequence, we can assert that the experience mixed research and design processes in an indissoluble way. Research is probably an inner principle of human-centred 
and collaborative design processes that allow collecting a large volume of contextual data.

Design network. The three national groups are the protagonists of the design network. The participation of the client is concentrated into the planning phase, while the users' one is concentrated into the fieldwork phase. In relation to the collaborative design approach, this is a limitation: a wider participation of both the client and the users along with all the design process should foster more insights, enriching the research phase results, their interpretation and the subsequent development.

Even if the Insitum's head office leaded the planning phase, during the rest of the process the national groups worked rather autonomously and horizontally, discussing the evolution of the process though online meetings and sharing the partial results of the phases.

However, the flow of information within the network was not continued, so as to allow a reciprocal fertilization between the groups, but concentrated at the end of every phase. In the ambit of the development of global projects, which are characterized by a space and time difference between the members of the developing design networks, a question remains open: how to share the process, rather than intermediary or final results.

Design consultancy as hub. Finally, it is important to notice that a US electronics company entrusted such important mission to a Mexican design consultancy. This is a reasonable way to explore the possibilities that the globalization is offering to global companies. Design consultancies based in the main cities of Latin America could serve as strategic gates for foreign corporations entering in the market of the region, because they have a deep knowledge about the socio-economic asset of the region.

Moreover, a consultancy located in an emerging country such as Mexico, is familiar with phenomena that are common to many other emerging countries, so as Insitum could led a research and design process that included an Indian part.

This way, globalization could be a possible specialization for Latin American design consultancies that hold the expertise to dialogue with foreign companies. They can work as mediators between different economic, social and cultural context.

\section{References}

BERTOLA, P.; TEIXEIRA, C. Design as a knowledge agent. how design as a knowledge processes embedded into organizations to foster innovation. Design Studies, v. 24, n. 2, p. 181-194, 2003. http://dx.doi.org/10.1016/S0142694X(02)00036-4.

BONSIEPE, G. EI diseño de la periferia. Barcelona: Gustavo Gili, 1985.

CELASCHI, F. et al. Design culture: from product to process: building a network to develop design processes in Latin countries. In: CHANGING THE CHANGE: DESIGN VISIONS PROPOSALS AND TOOLS, 1., 2008, Torino. Proceedings... Torino: Umberto Allemandi \& C., 2008. p. 534-545. Available from: <http://www.allemandi.com/ university/ctc.pdf $>$. Access in: 16 July 2015.

DE MORAES, D. Análise do design brasileiro: entre mimese e mestiçagem. São Paulo: Edgar Blücher, 2006.

HAGEL, J.; SEELY, B. J.; DAVISON, L. The power of pull: how small moves, smartly made, can set big things in motion. New York: Basic Books, 2010.

INTERNATIONAL ORGANIZATION FOR STANDARDIZATION - ISO. ISO 9241-210: ergonomics of human system interaction - part 210: human-centred design for interactive systems. Geneva: ISO, 2010.

MORIN, E. Introduction à la pensée complexe. Paris: Editions du Seuil, 2005.

QUESENBERY, W.; SZUC, D. Global UX: design and research in a connected world. Waltham, Massachusetts: Morgan Kaufmann, 2012.

SANDERS, E. Information, inspiration and co-creation. In: INTERNATIONAL CONFERENCE OF THE EUROPEAN ACADEMY OF DESIGN, 6., 2005, Bremen, Germany. Proceeding... University of the Arts, 2005.

SCRIVENER, S. A. R. Editorial. CoDesign, v. 1, n. 1, p. 1-4, 2005.

VANPATTER, G. K.; WHITNEY, P. Human-centered innovation: understanding the IIT Institute of Design. NextD Journal. ReRethinking Design, v. 2, n. 3, p. 1-12, 2004. Available from: <http://issuu.com/nextd/docs/conv7>. Access in: 3 July 2012.

VISOCKY O'GRADY, K.; VISOCKY O'GRADY, J. The information design handbook. Cincinnati: How Books, 2008. 